\title{
A Comparative Study on Efficacies of Posterior Microscopic Mini-open and Open Technique for Thoracolumbar Burst Fractures Accompanied With Severe Traumatic Spinal Stenosis
}

\section{Bin Zhang}

Guizhou Province Osteological Hospital https://orcid.org/0000-0003-3039-0866

\section{Yanna Zhou}

Zunyi Medical University

Hua Zou

Guizhou Aerospace Hospital

Zimo Lu

Affiliated Hospital of Zunyi Medical University

\section{Xin Wang}

Affiliated Hospital of Zunyi Medical University

Jun Ao ( $\sim$ Ao00jun@163.com )

Affiliated Hospital of Zunyi Medical University https://orcid.org/0000-0002-5658-8806

\section{Research Article}

Keywords: Thoracolumbar fracture, spinal stenosis, surgical microscope, minimally invasive

Posted Date: December 9th, 2021

DOl: https://doi.org/10.21203/rs.3.rs-1144725/v1

License: (c) (1) This work is licensed under a Creative Commons Attribution 4.0 International License.

Read Full License 


\section{Abstract \\ Purpose}

To compare the efficacies of minimal invasive decompression by posterior microscopic mini-open technique combined with percutaneous pedicle fixation (hereafter MOT) and traditional open surgeries in patients with severe traumatic spinal canal stenosis resulting from AO Type A3 or A4 thoracolumbar burst fractures and provide references for clinical treatment.

\section{Methods}

The clinical materials of 133 patients with severe traumatic spinal canal stenosis caused by AO Type A3 or A4 thoracolumbar burst fractures who underwent MOT (group A) or traditional open surgery (group B) were retrospectively enrolled. The patient demographic and radiological data were analyzed between the two groups.

\section{Results}

A total of 64 patients were finally recruited in this study. There were no significant differences in gender, age, follow-up time, injury mechanism, injured level, Arbeitsgemeinschaft für Osteosynthesefragen (AO) classification, American Spinal Injury Association (ASIA) score, Visual analogue scale (VAS) score and hospital stay between the two groups $(P>0.05)$. After procedures, the prevertebral height ratio $(P H R)$, the Cobb angle, and the mid-sagittal canal diameter compression ratio (MSDCR) in two groups were significantly improved $(P<0.05)$. Meanwhile, group $A$ with little intraoperative bleeding volume, and the VAS score improved better at post-operation and last follow up, but the operative time was longer $(P<0.05)$. The PHR, the Cobb angle in the two groups at the post-operation and last follow up without significantly different $(P>0.05)$, the MSDCR was improved at last follow up when compared with the value at post-operation $(P<0.05)$. However, the Cobb angle in group $A$ was well maintained than in group $B$ at last follow up $(P<0.05)$ and the MSDCR in group $B$ at last follow up improved better than in group $A$ $(P<0.05)$.

\section{Conclusions}

Both the MOT and traditional open surgery can treat $\mathrm{AO}$ type $\mathrm{A} 3$ and $\mathrm{A} 4$ thoracolumbar burst fractures accompanied with severe traumatic spinal stenosis effectively. The MOT has advantages including minimal invasion, extremely fine spinal canal decompression, lower intraoperative bleeding volume and obvious pain relief. We suggest that MOT should be preferentially selected for AO type A3 or A4 thoracolumbar burst fractures accompanied with severe traumatic spinal stenosis. 


\section{Introduction}

$90 \%$ of all spinal fractures are related to the thoracolumbar region, and burst fracture is a common form in this region, accounting for approximately $60 \%[1]$. Thoracolumbar fractures can make serious spinal cord injury[2]. Decompression surgery can help patients limit their secondary spinal cord injury and improve their neurological recovery after acute spinal cord injury. Short-segment posterior fixation, especially percutaneous minimally invasive fixation, for thoracolumbar fracture are well-accepted [3-6], but it is difficult to decompression and bone grafting for patients with severe traumatic spinal canal stenosis resulting from thoracolumbar burst fractures, when mid-sagittal canal diameter compression ratio $(\mathrm{MSDCR})>50 \%[3,7]$.

To date, the relative study of efficacies of minimal invasive decompression by posterior microscopic miniopen technique combined with percutaneous pedicle fixation (hereafter MOT) and traditional open surgery for thoracolumbar burst fractures accompanied with severe traumatic spinal canal stenosis has been rarely reported. The present study present comparisons between pre-and post-treatment and between groups were performed in the following.

\section{Methods}

\section{Demographics}

From January 2012 and January 2018, 133 consecutive patients with severe traumatic spinal canal stenosis caused by AO Type A3 or A4 thoracolumbar burst fractures who underwent MOT (group A) or traditional open surgeries (group B). 64 patients completed the 1-year follow-ups were retrospectively enrolled in this study. The inclusion criteria were: (I) patients with single segmental Arbeitsgemeinschaft für Osteosynthesefragen (AO) type A3 or A4 thoracolumbar fractures; and (II) intra-canal fracture

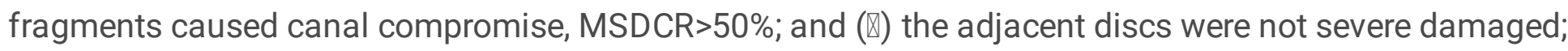
and $(\mathbb{Z})$ the posterior ligamentous complex (PLC) was not severe damaged; and $(\nabla)$ fractures within 2 weeks of injury. The exclusion criteria were: (I) patients with significant osteoporosis, endocrine diseases, tuberculosis, or other diseases which may affect the vertebral structure; (II) patients with congenital spinal stenosis; (III) patients with incomplete clinical records; and ( () a follow- up period of less than 12 months.

\section{Clinical and radiographic records}

All patient clinical and radiographic data were recorded at admission, postoperative, and last follow-up (12-24months after surgery). Clinical records included general date, follow-up time, injury mechanism, hospital stay, operative time, intraoperative bleeding volume, visual analogue scale (VAS) score[8], American Spinal Injury Association (ASIA) scores[9], AO spine injury classification[10].

Radiographic data contained the prevertebral height ratio (PHR)[3]; the injured vertebral Cobb angle; and the mid-sagittal canal diameter compression ratio (MSDCR) [11]. 


\section{MOT methods}

After general anesthesia, the patient was placed in a prone position and the abdomen was suspended. Percutaneous pedicle screw fixation was conducted under fluoroscopic guidance, where percutaneous pedicle screws were placed in the superior and inferior vertebra adjacent to the injured vertebra. An approximately $3 \mathrm{~cm}$ posterior midline incision, centered by the injured vertebra, was performed to expose lamina space of the injured vertebra. Then fenestration of the vertebral lamina was performed via the $3 \mathrm{~cm}$ incision under microscopy, followed by observing and pushing the fracture fragments into the vertebral body using the L-shaped operative tool, followed by longitudinal distraction of the vertebral body anterior margin. Subsequently, using a curette to find the fracture lines at the posterior wall of the injured vertebral body and achieve the anterior and middle column reduction and manufacture a diameter approximately $5 \mathrm{~mm}$ bone grafting channel. After confirmation of satisfactory reduction using fluoroscopy, autologous bones or allograft bones were implanted in the injured vertebral body via bone grafting channel, until 3-4mm deep from the posterior wall of the injured vertebral body. After adequate hemostasis, the wound was flushed, and the drainage tube was placed as necessary, incisions were sutured layer by layer. See figure 1.

\section{Statistical analysis}

Statistical analysis SPSS20.0 statistical software (IBM Corp., Armonk, NY, USA) was used for data analysis. Quantitative data were presented as mean \pm standard deviation. Within-group comparisons of PHR, Cobb angle, MSDCR and VAS score at multiple time points were used repeated measurement analysis of variance combined with post Bonferroni test. Mann-Whitney U-test was used for ASIA scores within-group comparisons. Age, follow-up time, hospital stay, operative time, intraoperative bleeding volume, PHR, Cobb angle, MSDCR and VAS score between two groups were compared by independentsample $t$ tests. Gender, injury mechanism, injured level, AO classification between two groups were compared by Chi-square test. A probability less than 0.05 was considered statistically significant.

\section{Results}

\section{Comparison of general conditions}

A total of 64 patients were finally recruited, 69 patients with incomplete clinical records or lost to follow up were excluded. These 64 patients included 28 patients had treatment with MOT were classified as group A (21 males and 7 females), and 36 patients had treatment with traditional open surgeries were classified as group B (25 males and 11 females). Statistical analysis revealed that there were no significant intergroup differences in gender, age, follow-up time, injury mechanism, injured level, AO classification, ASIA score, and MSDCR between the two groups (all $P>0.05$, Table 1). 
Table 1

Comparison of general conditions

\begin{tabular}{|c|c|c|c|c|c|}
\hline \multicolumn{2}{|l|}{ Variables } & \multirow{2}{*}{$\begin{array}{l}\text { Group } \\
A(n=28) \\
21\end{array}$} & \multirow{2}{*}{$\begin{array}{l}\text { Group } \\
\text { B(n=36) } \\
25\end{array}$} & \multirow{3}{*}{$\begin{array}{l}\text { Statistical } \\
\text { value } \\
X^{2}=0.240\end{array}$} & \multirow{3}{*}{$\begin{array}{l}P \\
\text { value } \\
0.624\end{array}$} \\
\hline Gender & Male & & & & \\
\hline & Female & 7 & 11 & & \\
\hline Age (years) & & $42.11 \pm 10.77$ & $41.64 \pm 13.23$ & $t=0.152$ & 0.880 \\
\hline $\begin{array}{l}\text { Follow-up time } \\
\text { (days) }\end{array}$ & & $16.46 \pm 4.01$ & $15.72 \pm 4.91$ & $t=0.648$ & 0.519 \\
\hline \multirow{4}{*}{$\begin{array}{l}\text { Injury } \\
\text { mechanism }\end{array}$} & Fall from height & 21 & 26 & \multirow[t]{4}{*}{$X^{2}=1.345$} & \multirow[t]{4}{*}{0.789} \\
\hline & Car accident & 4 & 6 & & \\
\hline & Fall & 2 & 1 & & \\
\hline & $\begin{array}{l}\text { Heavy object smashing } \\
\text { injury }\end{array}$ & 1 & 3 & & \\
\hline \multirow[t]{4}{*}{ Injured level } & $\mathrm{T} 11$ & 1 & 2 & \multirow[t]{4}{*}{$X^{2}=1.529$} & \multirow[t]{4}{*}{0.738} \\
\hline & T12 & 4 & 6 & & \\
\hline & L1 & 14 & 21 & & \\
\hline & L2 & 9 & 7 & & \\
\hline \multirow[t]{2}{*}{ AO classification } & A3 & 19 & 26 & \multirow[t]{2}{*}{$X^{2}=0.144$} & \multirow[t]{2}{*}{0.705} \\
\hline & A4 & 9 & 10 & & \\
\hline \multirow[t]{5}{*}{ ASIA score } & $A$ & 0 & 8 & \multirow[t]{5}{*}{$Z=1.570$} & \multirow[t]{5}{*}{0.116} \\
\hline & B & 0 & 6 & & \\
\hline & C & 12 & 5 & & \\
\hline & $\mathrm{D}$ & 13 & 11 & & \\
\hline & $E$ & 3 & 6 & & \\
\hline MSDCR(\%) & & $55.91 \pm 6.70$ & $56.21 \pm 7.10$ & $t=0.167$ & 0.868 \\
\hline
\end{tabular}

\section{Perioperative data}


All procedures were completed successfully. No significant difference was found concerning duration of hospital stay between both groups ( $P>0.05$, Table 2 ). The mean operative time was longer and the mean intraoperative bleeding volume was less in group A when compared to that in group $B$. The difference was statistically significant (all $\mathrm{P}<0.05)$.

Table 2

Comparison of hospital stay, operative time, intraoperative bleeding volume

\begin{tabular}{|lllll|}
\hline Time & Group A(n=28) & Group B(n=36) & $\boldsymbol{t}$ values & $\boldsymbol{P}$ values \\
\hline Hospital stay (days) & $12.54 \pm 3.04$ & $13.89 \pm 3.76$ & 1.550 & 0.126 \\
\hline Operative time (min) & $216.39 \pm 38.11$ & $165.22 \pm 24.15$ & 6.549 & 0.001 \\
\hline Intraoperative bleeding volume $(\mathrm{mL})$ & $197.68 \pm 136.15$ & $340.00 \pm 150.54$ & 3.910 & $<0.001$ \\
\hline
\end{tabular}

\section{Radiographic findings}

The PHR, the Cobb angle, and the MSDCR in the two groups at post-operation and last follow-up were significantly improved when compared with the preoperative value (all $\mathrm{P}<0.05$, Table 3 ). The PHR, the Cobb angle in the two groups at the post-operation and last follow up without significantly different $(P>0.05)$, but the MSDCR was improved at last follow up when compared with the value at post-operation $(P<0.05)$.

The PHR in group B was heavier than in group $A$ at the pre-operation $(P<0.05)$, but there was no significantly difference at post-operation and last follow up $(P>0.05)$. The Cobb angle in group $B$ was heavier than in group $A$ at the pre-operation $(P<0.05)$, same as above, there was no significantly difference at post-operation $(P>0.05)$, but the Cobb angle in group $A$ was well maintained than in group $B$ at last follow up $(P<0.05)$. The MSDCR in two groups without significantly difference at pre- and postoperation $(P>0.05)$, however, the MSDCR in group $B$ at last follow up improved better than in group $A$ $(P<0.05)$. 
Table 3

Results for within-group and between-group comparisons at each time point

\begin{tabular}{|c|c|c|c|c|c|}
\hline Variables & Time & Group $A(n=28)$ & Group $B(n=36)$ & $t$ values & $P$ values \\
\hline \multirow[t]{5}{*}{ PHR (\%) } & Pre-operation & $60.77 \pm 9.75$ & $46.65 \pm 11.91$ & 5.085 & $<0.001$ \\
\hline & Post-operation & $97.79 \pm 3.27 *$ & $97.56 \pm 7.29 *$ & 0.157 & 0.875 \\
\hline & Last follow-up & $96.84 \pm 3.49 *$ & $96.83 \pm 7.62^{\star}$ & 0.004 & 0.997 \\
\hline & $F$ values & 183.492 & 375.564 & & \\
\hline & $P$ values & $<0.001$ & $<0.001$ & & \\
\hline \multirow[t]{5}{*}{ Cobb angle $\left(^{\circ}\right)$} & Pre-operation & $9.71 \pm 5.08$ & $14.94 \pm 5.72$ & 3.811 & $<0.001$ \\
\hline & Post-operation & $5.32 \pm 2.16^{*}$ & $5.89 \pm 3.23^{\star}$ & 0.800 & 0.427 \\
\hline & Last follow-up & $4.96 \pm 2.22^{*}$ & $6.44 \pm 3.35^{\star}$ & 2.017 & 0.048 \\
\hline & $F$ values & 17.592 & 43.882 & & \\
\hline & $P$ values & $<0.001$ & $<0.001$ & & \\
\hline \multirow[t]{5}{*}{ MSDCR (\%) } & Pre-operation & $55.91 \pm 6.70$ & $56.21 \pm 7.10$ & 0.167 & 0.868 \\
\hline & Post-operation & $10.11 \pm 4.99 *$ & $8.34 \pm 2.77^{\star}$ & 1.799 & 0.077 \\
\hline & Last follow-up & $8.15 \pm 4.83^{\star \#}$ & $6.22 \pm 2.54^{\star \#}$ & 2.061 & 0.044 \\
\hline & $F$ values & 499.306 & 907.014 & & \\
\hline & $P$ values & $<0.001$ & $<0.001$ & & \\
\hline $\begin{array}{l}\text { PHR, the prever } \\
\text { A, MOT group; } \\
0.05 \text { compared }\end{array}$ & $\begin{array}{l}\text { al height ratio; } \\
\text { up } B \text {, traditional } \\
\text { h postoperative. }\end{array}$ & $\begin{array}{l}\mathrm{CR} \text {, the mid-sagi } \\
\text { n surgeries group }\end{array}$ & $\begin{array}{l}\text { canal diameter } \\
b<0.05 \text { compare }\end{array}$ & $\begin{array}{l}\text { pression } \\
\text { jth preop }\end{array}$ & $\begin{array}{l}\text { io; Group } \\
\text { tive; }{ }^{\#} \mathrm{P}<\end{array}$ \\
\hline
\end{tabular}

\section{Visual analogue scale (VAS) score}

There was no significant difference in VAS score between the groups before operation ( $P>0.05$, Table 4$)$. The VAS score on postoperative day 1 and at the last follow up were significantly lower than the respective preoperative values in both groups $(P<0.05)$. However, the improvement in the VAS score was significantly more favorable in Group A than in Group B $(P<0.05)$. 
Table 4

Comparison of VAS score

\begin{tabular}{|lllll|}
\hline Time & Group A(n=28) & Group B(n=36) & $t$ values & $P$ values \\
\hline Pre-operation & $7.04 \pm 0.92$ & $6.97 \pm 0.97$ & 0.976 & 0.333 \\
\hline postoperative day 1 & $2.89 \pm 0.69 *$ & $3.39 \pm 0.87 *$ & 2.475 & 0.016 \\
\hline Last follow-up & $0.36 \pm 0.49 * \#$ & $0.67 \pm 0.54{ }^{*}$ & 2.386 & 0.020 \\
\hline Fvalues & 577.701 & 775.714 & & \\
\hline$P$ values & $<0.001$ & $<0.001$ & & \\
\hline *P $<0.05$ compared with preoperative; ${ }^{*} \mathrm{P}<0.05$ compared with postoperative day 1. \\
\hline
\end{tabular}

\section{American Spinal Injury Association (ASIA) scores}

The pre- and last follow-up differences in the two groups were statistically significant for ASIA scores comparisons $(P<0.05$, Table 5$)$.

Table 5

Comparison of ASIA scores

\begin{tabular}{|lllll|}
\hline ASIA score & Group A & & Group B & \\
\cline { 2 - 5 } & Pre-operation & Last follow-up & Pre-operation & Last follow-up \\
\hline A & 0 & 0 & 8 & 2 \\
\hline B & 0 & 0 & 6 & 3 \\
\hline C & 12 & 1 & 5 & 6 \\
\hline D & 13 & 14 & 11 & 11 \\
\hline E & 3 & 13 & 6 & 14 \\
\hline$Z$ value & 3.860 & & 2.593 & \\
$P$ value & $<0.001$ & & 0.010 & \\
\hline $\begin{array}{l}\text { The rank order of ASIA scores in this article were (A)-1, (B)-2, (C)-3, (D)-4, and (E)-5; Group A: } \\
\text { preoperative mean rank nontagged 20.73 and the last follow up mean rank nontagged 36.27; Group } \\
\text { B: preoperative mean rank nontagged 30.29 and the last follow up mean rank nontagged 42.71 }\end{array}$ \\
\hline
\end{tabular}

\section{A typical case of MOT}


A 47-year-old male patient was diagnosed AO type A4 fractures at the L2 level with a large posterior wall retropulsed fragment into the spinal canal causing significant spinal canal encroachment, and had ASIA E neurological status. After MOT treatment, the prevertebral height and Cobb angle improved, and the fragment in the spinal canal had good reduction. At the time of last follow-up, the patient had ASIA E neurological status, and the radiographic results showed good fracture union. Although partial bone graft resorption was observed, the prevertebral height, Cobb angle and the spinal canal patency were wellmaintained, see Figure 2.

\section{Discussion}

\section{The standard of severe traumatic spinal stenosis caused by thoracolumbar burst fractures}

The standard of severe traumatic spinal stenosis of thoracolumbar fractures remains controversial. Wolter[12] considered that retropulsed fragment into the spinal canal cause MSDCR $>2 / 3$ as severe spinal stenosis. Meves et al.[13] believed that there is a positive correlation between narrowing of the spinal canal and the severity of the incomplete neurological deficit. When patients with 25,50 , and $75 \%$ narrowing of the thoracolumbar spinal canal, the probability of neurological deficit may be 12,41 , and $78 \%$, and in the lumbar spinal canal it was 8,30 , and $68 \%$, respectively. Based on our previous experience, when MSDCR $>50 \%$, patients have a high probability of neurological deficit, coincided with the findings of previous studies of Mohanty et al[14]. We therefore recommend that MSDCR $>50 \%$ is a standard of severe traumatic spinal stenosis, because of difficulty in fracture reduction and high probability of neurological deficit.

\section{Minimally invasive and effective}

MOT combines the advantages of minimally invasive procedures and open surgeries: a) percutaneous pedicle screw fixation and fenestration of the vertebral lamina were performed via the minimally invasive incisions maximizing protected the paraspinal muscle and the posterior ligamentous complex (PLC), so that it can maintain thoracolumbar segmental stability and reduce post-operative pain and bleeding volume[4]; b) the fracture fragments can been directly and indirectly pressed into the fractured vertebral body using the L-shaped operative tool and the elastic tension of the posterior longitudinal ligament; $\mathrm{c}$ ) the anterior and middle column satisfactory reduction and adequate bone graft can achieve via the spinal canal (Figure 2). In these studies, the postoperative PHR, Cobb angles, MSDCR were improved compared with preoperative values $(P<0.05)$. Thus, it was suggested that both the MOT and traditional open surgery may achieve decompression of the spinal canal, correct spinal deformity and rebuild spinal stability effectively. The PHR, the Cobb angle in the two groups at the post-operation and last follow up without significantly different $(P>0.05)$, but the Cobb angle in group $A$ was well maintained than in group $B$ at last follow up $(P<0.05)$. It was shown that both procedures can restore and maintain spinal stability, however, the MOT is better than traditional open surgery. The VAS score of the two groups were significantly lower after surgeries $(P<0.05)$, meanwhile, the VAS score of group A was lower than that in the group $B$ on 
postoperative day 1 and at the last follow up $(P<0.05)$. So excellent pain relief by the MOT could be demonstrated.

\section{The significance of using a surgical microscope in MOT}

Because of the incision for decompression was small and deep, insufficient view of the surgical area and inadequate light results the decompression is so difficult and not safe that clinicians may choose a traditional open surgery. The surgical microscope can compensate for the above limitations. The major advantages of the microscope include better illumination, magnification and coaxial vision, these can avoid spinal cord and nerve root injuries as well as dural lesions[15]. The intraoperative bleeding volume of MOT was less than traditional open surgeries $(P<0.05)$. One major reason stem from using surgical microscope, as the perivertebral venous plexus anatomy be identified intraoperatively and controlled with compression hemostasis and electrocautery accurately[16].

\section{Experience in MOT}

\section{Details of decompression and reduction}

Depending on the severity compression of the nerve root and spinal cord, different order of decompression and reduction should be considered[17]. When neural tissue be compressed seriously or stuck by bony fragments in the spinal canal or fractured lamina, especially at the T11-12 vertebral level, the decompression and reduction should in the order of: fenestration $\rightarrow$ longitudinal distraction $\rightarrow$ reduction by using a curette. When neural tissue without serious compression or incarceration, the decompression and reduction should in the order of: longitudinal distraction $\rightarrow$ fenestration $\rightarrow$ reduction by using a curette. Fenestration should be performed on the side of neural tissue be compressed or injured seriously. Unilateral fenestration is recommended unless bilateral lamina or lateral wall of the spinal canal were fractured seriously.

\section{Bone graft skills}

In our passed study, we found sagittal fracture lines existed over the pedicle horizontal in thoracolumbar fractures accompanied with loss of vertebral body height. This region is overlap with the interlaminar space, so a $3 \mathrm{~cm}$ incision at this region is sufficient for decompression, reduction and bone graft. Because of the adjacent discs and PLC were not severe damaged, the MOT does not require posterolateral fusion or interbody fusion, the fixation by posterior approach and bone graft can make the intervertebral spaces does not change significantly, then anterior column will be spontaneous fusion[6,18-20]. In this study, the postoperative PHR and Cobb angles improved significantly $(\mathrm{P}<0.05)$ and remained stable at last followup $(P<0.05)$. These results coincide with the points of view above.

\section{Treatment strategy for the spinal canal}

It is not necessary to achieve the anatomic reduction if reduction is difficult, to avoid damage to the spinal cord or nerves. Miyashita et al. [21]found that there is no significant effect on the recovery of neurological function when MSDCR $<30 \%$. When decompression removed the fragments or soft tissues 
which compress the neural structures, bone resorption can complete spinal canal remodeling. This is related to intraspinal neurilemmoma and venous pulsation[22]. The results of this study showed that the MSDCR in two groups without significantly difference at pre- and post-operation $(P>0.05)$, revealed that both the MOT and traditional open surgery have the competence to afford effective decompression of the spinal canal. However, the MSDCR in traditional open surgery at last follow up: $6.22 \pm 2.54 \%$ improved better than in the MOT: $8.15 \pm 4.83 \%(P<0.05)$, the mechanisms involved remain unclear and require further investigation.

\section{Limitations in this study}

It was a retrospective study with a small sample and short time follow up. The long-term effectiveness and advantages of MOT need to expand the sample size for further research. Meanwhile, the effectiveness after removing the internal fixation would be needed to investigate further.

\section{Conclusions}

Both the MOT and traditional open surgery can treat AO type A3 and A4 thoracolumbar burst fractures accompanied with severe traumatic spinal stenosis effectively. The MOT has advantages including minimal invasion, extremely fine spinal canal decompression, lower intraoperative bleeding volume and obvious pain relief. We suggest that MOT should be preferentially selected for AO type A3 or A4 thoracolumbar burst fractures accompanied with severe traumatic spinal stenosis.

\section{Abbreviations}

MOT: Minimal invasive decompression by posterior microscopic mini-open technique combined with percutaneous pedicle fixation; AO: Arbeitsgemeinschaft für osteosynthesefragen classification; ASIA: American spinal injury association score; VAS: Visual analogue scale score; PHR: Prevertebral height ratio; MSDCR: Mid-sagittal canal diameter compression ratio; PLC: Posterior ligamentous complex.

\section{Declarations}

\section{Acknowledgements}

We thank the reviewers and editors for their helpful comments on this article.

\section{Authors' contributions}

All authors read and approved the final manuscript.

\section{Funding}

None.

\section{Availability of data and materials}


The datasets used and/or analyzed during the current study are available from the corresponding author on reasonable request.

\section{Ethics approval and consent to participate}

This study was conducted in accordance with the declaration of Helsinki. This study was conducted with the approval from the Ethic committee of Affiliated Hospital of Zunyi Medical University.

\section{Consent for publication}

written informed consent to publish the clinical details and images of the patient was obtained.

\section{Competing interests}

The authors declare that they have no competing interests.

\section{References}

1. Huang J, Zhou L, Yan Z, Zhou Z, Gou X. Effect of manual reduction and indirect decompression on thoracolumbar burst fracture: a comparison study. J Orthop Surg Res 2020;15:532-9. https://doi.org/10.1186/s13018-020-02075-w.

2. Sharwood LN, Mueller H, Ivers RQ, Vaikuntam B, Driscoll T, Middleton JW. The epidemiology, cost, and occupational context of spinal injuries sustained while' working for income' in NSW: a recordlinkage study. Int J Environ Res Public Health 2018;15:2121-9.

https://doi.org/10.3390/ijerph15102121.

3. Yao W, Zhou T, Huang K, Dai M, Mo F, Xu J, et al. A comparison of monoaxial pedicle screw versus polyaxial pedicle screw in short-segment posterior fixation for the treatment of thoracolumbar fractured vertebra. Ann Transl Med 2021;9:669-76. https://doi.org/10.21037/atm-21-881.

4. Wang X, Liu Y, Wang X, Chen H, Cao P, Tian Y, et al. Beneficial effects of percutaneous minimally invasive surgery for patients with fractures in the thoracic spine. Exp Ther Med 2018;16:5394-9. https://doi.org/10.3892/etm.2018.6887.

5. Smits AJ, Polack M, Deunk J, Bloemers FW. Combined anteroposterior fixation using a titanium cage versus solely posterior fixation for traumatic thoracolumbar fractures: a systematic review and metaanalysis. J Craniovertebr Junction Spine 2017;8:168-78. https://doi.org/10.4103/jcvjs.JCVJS_8_17.

6. Liang C, Liu G, Liang G, Zheng X, Yin D, Xiao D, et al. Healing pattern classification for thoracolumbar burst fractures after posterior short-segment fixation. BMC Musculoskelet Disord 2020;21:373-82. https://doi.org/10.1186/s12891-020-03386-z.

7. Li X, Guan Z, Chen X, Chen B, Kong L, Han J, et al. Modified minimally invasive technique for decompression and reduction of thoracolumbar burst fracture with neurological symptoms: technical note. J Orthop Surg Res 2021;16:626-32. https://doi.org/10.1186/s13018-021-02783-x. 
8. Krasowska K, Skrobot W, Liedtke E, Sawicki P, Flis DJ, Dzik KP, et al. The preoperative supplementation with vitamin $D$ attenuated pain intensity and reduced the level of pro-inflammatory markers in patients after posterior lumbar interbody fusion. Front Pharmacol 2019;10:527-34. https://doi.org/10.3389/fphar.2019.00527.

9. Asia, Committee ISIS. The 2019 revision of the International Standards for Neurological Classification of Spinal Cord Injury (ISNCSCI)-What's new? Spinal Cord 2019;57:815-7. https://doi.org/10.1038/s41393-019-0350-9.

10. Reinhold M, Audige L, Schnake KJ, Bellabarba C, Dai LY, Oner FC. AO spine injury classification system: a revision proposal for the thoracic and lumbar spine. Eur Spine J 2013;22:2184-201. https://doi.org/10.1007/s00586-013-2738-0.

11. Hashimoto T, Kaneda K, Abumi K. Relationship between traumatic spinal canal stenosis and neurologic deficits in thoracolumbar burst fractures. Spine 1988;13:1268-72. https://doi.org/10.1097/00007632-198811000-00011.

12. Wolter D. Recommendation for the classification of spinal injuries. Unfallchirurg 1985;88:481-4.

13. Meves R, Avanzi O. Correlation between neurological deficit and spinal canal compromise in 198 patients with thoracolumbar and lumbar fractures. Spine 2005;30:787-91. https://doi.org/10.1097/01.brs.0000157482.80271.12.

14. Mohanty SP, Bhat NS, Abraham R, Ishwara Keerthi C. Neurological deficit and canal compromise in thoracolumbar and lumbar burst fractures. J Orthop Surg (Hong Kong) 2008;16:20-3. https://doi.org/10.1177/230949900801600105.

15. Damodaran O, Lee J, Lee G. Microscope in modern spinal surgery: advantages, ergonomics and limitations. ANZ J Surg 2013;83:211-4. https://doi.org/10.1111/ans.12044.

16. Wang K, Shang F, Jian FZ, Wu H. Effect of simultaneous surgical treatment in scoliosis associated with intraspinal abnormalities: a retrospective study. Exp Ther Med 2020;20:108-14. https://doi.org/10.3892/etm.2020.9236.

17. Bains RS, Althausen PL, Gitlin GN, Gupta MC, Benson DR. The role of acute decompression and restoration of spinal alignment in the prevention of post-traumatic syringomyelia: case report and review of recent literature. Spine (Phila Pa 1976) 2001;26:399-402. https://doi.org/10.1097/00007632-200109010-00028.

18. Zhong W, Liang X, Luo X, Huang T, Quan Z. Complications rate of and risk factors for the unplanned reoperation of degenerative lumbar spondylolisthesis in elderly patients: a retrospective single-Centre cohort study of 33 patients. BMC Geriatr 2020;20:301-6. https://doi.org/10.1186/s12877-020-017172.

19. Farcy JP, Weidenbaum M, Glassman SD. Sagittal index in management of thoracolumbar burst fractures. Spine (Phila Pa 1976) 1990;15:958-65. https://doi.org/10.1097/00007632-19900900000022.

20. Kim BG, Dan JM, Shin DE. Treatment of thoracolumbar fracture. Asian Spine J 2015;9:133-46. https://doi.org/10.4184/asj.2015.9.1.133. 
21. Miyashita T, Ataka $\mathrm{H}$, Tanno T. Clinical results of posterior stabilization without decompression for thoracolumbar burst fractures: is decompression necessary? Neurosurg Rev 2012;35:447-55. https://doi.org/10.1007/s10143-011-0363-0.

22. Sjostrom L, Jacobsson O, Karlstrom G, Pech P, Rauschning W. Spinal canal remodelling after stabilization of thoracolumbar burst fractures. Eur Spine J 1994;3:312-7. https://doi.org/10.1007/BF02200143.

\section{Figures}

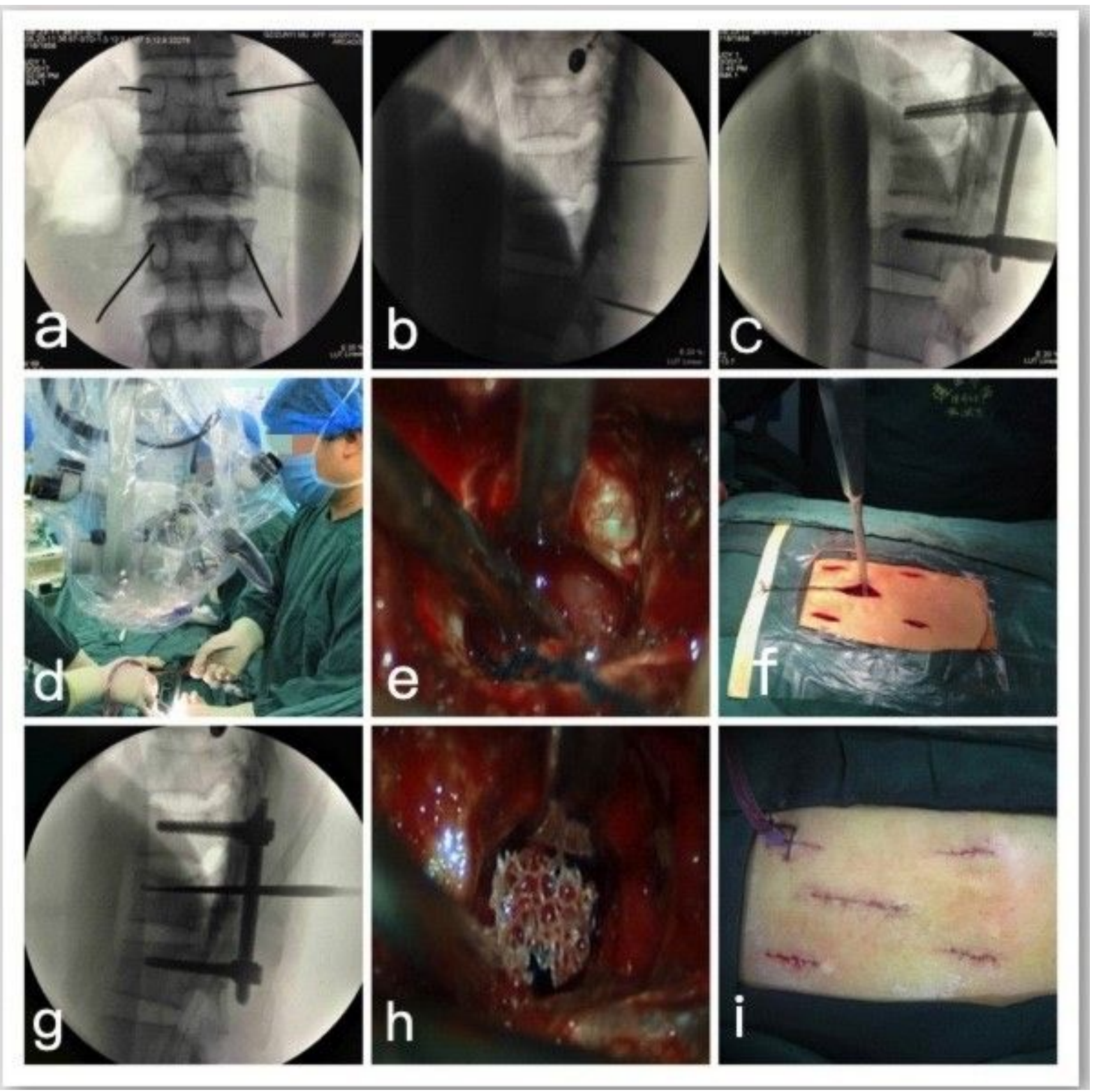

\section{Figure 1}

MOT methods a \& b. Four guide needles were inserted into the adjacent vertebral pedicles under fluoroscopic guidance; c. the positions of the percutaneous pedicle screws were confirmed radiographically after implantation; $d$. fenestration of the vertebral lamina was performed via the $3 \mathrm{~cm}$ 
incision under microscopy; e. observing and pushing the fracture fragments into the vertebral body under microscopy; f. using a curette to achieve the anterior and middle column reduction; $g$. the satisfactory reduction was confirmed by lateral radiograph; $h$. autologous bones and allograft bones were implanted in the injured vertebral body under microscopy; i. a drainage tube was placed and incision was intradermal sutured.
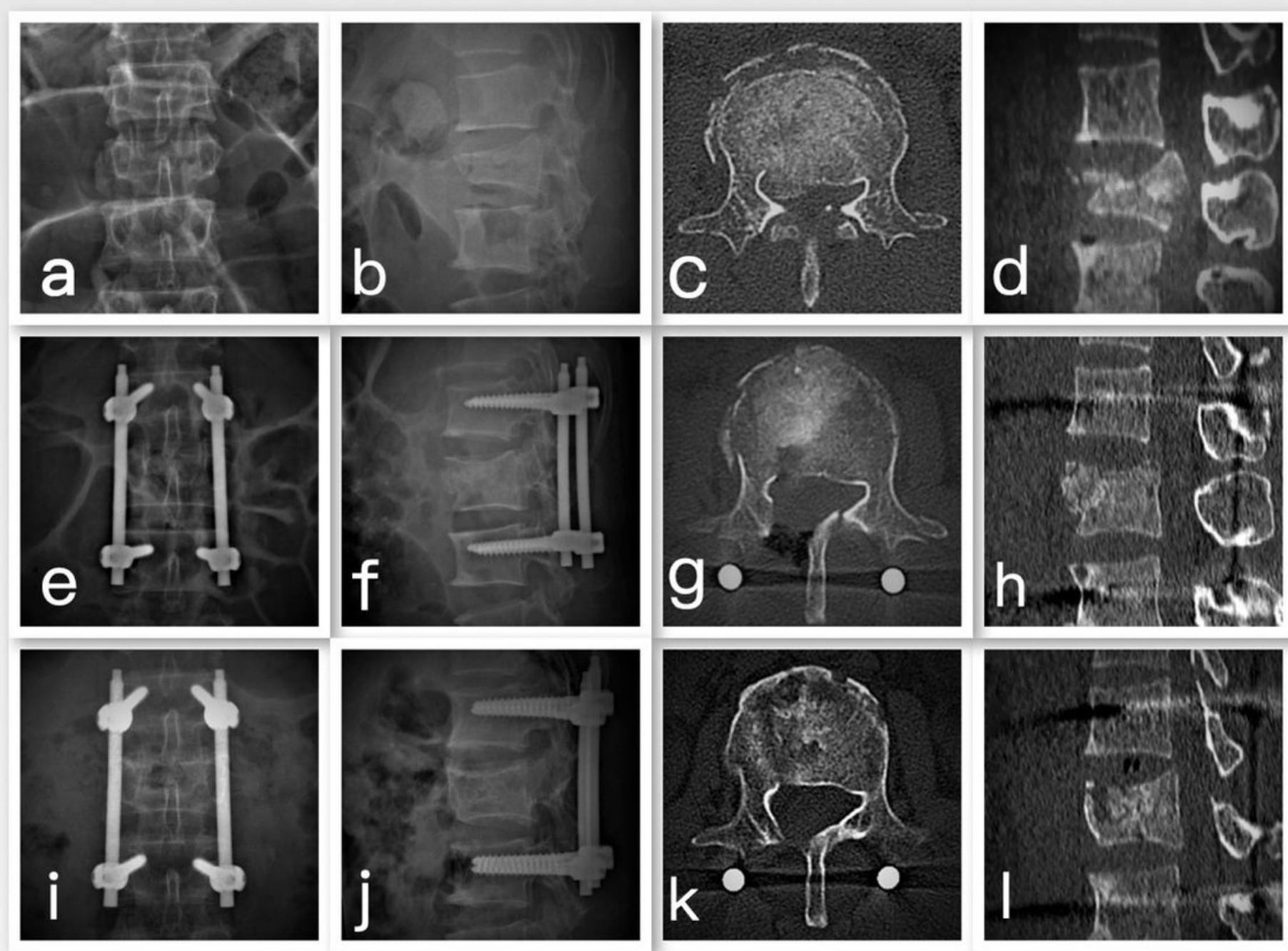

\section{Figure 2}

A 47-year-old man with $\mathrm{L} 2$ burst fracture (AO type $\mathrm{A} 4$ ) accompanied with severe traumatic spinal stenosis (a) Preoperative anteroposterior radiograph; (b) Preoperative lateral radiograph; (c) Preoperative CT axial view; (d) Preoperative CT sagittal view; (e) Postoperative anteroposterior radiograph; (f) Postoperative lateral radiograph; (g) Postoperative CT axial view; (h) Postoperative CT sagittal view; (i) 2-years postoperative anteroposterior radiograph; (j) 2-years postoperative lateral radiograph; (k) 2-years postoperative CT axial view; (I) 2-years postoperative CT sagittal view 